\title{
The effect of technology-organization-environment on adoption decision of big data technology in Thailand
}

\author{
Wanida Saetang, Sakchai Tangwannawit, Tanapon Jensuttiwetchakul \\ Faculty of Information Technology and Digital Innovation, \\ King Mongkut's University of Technology North Bangkok, Thailand
}

\begin{abstract}
Article Info
Article history:

Received Mar 20, 2020

Revised May 30, 2020

Accepted Jun 14, 2020

Keywords:

Big data technology

Diffusion of innovation

Structural equation modeling

TOE framework

ABSTRACT

Big data technology (BDT) is being actively adopted by world-leading organizations due to its expected benefits. However, most of the organizations in Thailand are still in the decision or planning stage to adopt BDT. Many challenges exist in encouraging the BDT diffusion in businesses. Thus, this study develops a research model that investigates the determinants of BDT adoption in the Thai context based on the technology-organizationenvironment (TOE) framework and diffusion of innovation (DOI) theory. Data were collected through an online questionnaire. Three hundred IT employees in different organizations in Thailand were used as a sample group. Structural equation modeling (SEM) was conducted to test the hypotheses. The result indicated that the research model was fitted with the empirical data with the statistics: Normed Chi-Square $=1.651$, GFI $=0.895$, AFGI $=0.863, \quad \mathrm{NFI}=0.930, \quad \mathrm{TLI}=0.964, \mathrm{CFI}=0.971, \quad \mathrm{SRMR}=0.0392$, and RMSEA $=0.046$. The research model could, at $52 \%$, explain decision to adopt BDT. Relative advantage, top management support, competitive pressure, and trading partner pressure show significant positive relation with BDT adoption, while security negatively influences BDT adoption.
\end{abstract}

Copyright (C) 2020 Institute of Advanced Engineering and Science. All rights reserved.

\section{Corresponding Author:}

Wanida Saetang,

Faculty of Information Technology and Digital Innovation,

King Mongkut's University of Technology North Bangkok,

1518 Pracharat 1 Road, Wongsawang, Bangsue, Bangkok 10800, Thailand.

Email: s5807011910062@email.kmutnb.ac.th

\section{INTRODUCTION}

Big data technology (BDT) has recently achieved its importance in the $21^{\text {st }}$ century. BDT is a paradigm shift from traditional technologies that could not manage a large volume of digital data within an acceptable time. The traditional technologies have limited storage capacity, and are inflexible, inefficient and expensive [1]. In 2003, Google published the Google file system, which was the origin of "Hadoop" [2]. Hadoop is an open-source software for reliable, scalable, and distributed computing. The Hadoop platform consists of two main components: the hadoop distributed file system (HDFS) and the MapReduce framework [3]. Furthermore, developers can add modules on top of Hadoop according to their objectives as well as their specific requirements. As a result, various types of applications and technologies have been developed.

Nowadays, companies and organizations are aware of the value of big data, which is becoming one of the essential factors for building competitiveness. In terms of advantages, BDT has been diffused in all industries for both research and production purposes. At the same time, adoption of BDT might have an impact on the business process, information system usage, and organizational structures [4]. These would make the adoption of BDT challenging because it might lead to temporary inefficiency in that organization. For this reason, it is important to know and understand the factors that affect the adoption of technology and the theoretical models of acceptance before implementing it in an organization [5]. 
As for the situation of big data in Thailand, BDT played a major role during the government's development to a more advanced level, Thailand 4.0. The big data market was valued at 6 billion baht in 2017 and had been expected to grow to 13.2 billion baht in 2020 [6]. The growth in market value shows that most organizations in Thailand invest in BDT. This strongly reflects the interest and growth of big data in Thailand. Also, the research by IPG Mediabrands, which explored BDT in Thailand in 2018 found that $19 \%$ of business sections had used BDT and succeeded, $40 \%$ was still in the experimental stage and the remaining $40 \%$ might be in the decision or planning stage [6]. This exploration indicates that organizations in Thailand are enthusiastic about adopting this technology.

However, there are various factors that can affect an organization's decision to adopt BDT. Therefore, this paper will focus on, 1) studying the factors influencing BDT adoption in organizations, 2) developing the BDT adoption model that fits the context of Thailand. The result of this study will deliver knowledge that can be applied as well as used in exploration and preparation for the adoption of BDT in organizations. This can also be applied for policy regulations in the government as well as in private sectors to support BDT adoption. We hope this study may promote acceptance of BDT enhancing Thailand's competitiveness in the world.

This paper consists of six sections. The second section covers the theoretical background, hypotheses and the study model. The third section describes the research methodology and data collection. The four section, we present the research results and hypotheses testing. In section five, we conclude this research. In the last section, we describe the implications for research and practical.

\section{THEORETICAL BACKGROUND}

In this section, the first part includes the definition and adoption of big data. The following part provides the theoretical foundations of the technology-organization-environment (TOE) framework. Lastly, hypotheses are proposed to test the conceptual model.

\subsection{Big data}

Big data is a field that deals with the storage and processing of large collections of data that are often from diverse data sources. The official definition: "Big data is high-volume, high-velocity, and highvariety information assets that demand cost-effective, innovative forms of information processing for enhanced insight and decision making" [7]. In this definition, the main properties of big data have three V's: volume, velocity, and variety. Volume refers to the amount of data generated continuously from various sources such as mobile devices and online applications. Velocity refers to the speed at which data are being generated and the speed of data processing to extract insights and useful information. Variety refers to the many types of data (structured, semi- structured, and unstructured) and come from heterogeneous sources [8].

Big data is larger, more complex data sets, which is difficult to process using traditional database management tools and traditional data processing applications [9]. From different big data projects around the world, there are many solutions and new technologies [1]. In fact, the new technologies that have been developed are completely different from traditional technologies in two domains.

Firstly, big data storage is completely different from relational database technology that works together with traditional information systems. Data collected from external sources are often not in a format or structure that can be directly processed, so "data wrangling" [10] is necessary. Generally, data wrangling begins with the extraction of the raw data from data sources, followed by wrangling the data either using algorithms or parsing into predefined data structures. Eventually, the prepared data must be stored again in the database for future use. Due to the required storage for multiple copies, innovative storages were created to provide cost-effective and highly scalable storage solutions. Examples of big data storage concepts include clusters, file systems and distributed files systems, and NoSQL [10].

Secondly, big data processing is different from centralized processing in a traditional relational database. Big data is often processed in parallel through distributed processing at the location where data are stored. Moreover, big data has the velocity characteristic, so there are many ways for big data processing, such as distributed data processing, parallel data processing, and cluster processing [10].

Data processed by big data solutions can be used directly by enterprise applications or can be fed into a data warehouse to enhance existing data. The results of big data processing can lead to many insights and benefits such as improved decision-making, increased productivity, reduce costs, accurate predictions, and fraud detection. Although, organizations can exploit the benefits of BDT, they must also be aware of the risks. In addition, investing in BDT requires a constant change in the organization to fully receive the benefits [11]. Therefore, the business analysts and executives are supposed to be aware of this change. Considering all these reasons, the following sections show the research hypotheses that have been used to investigate the adoption of BDT in organizations. 


\subsection{Determinants of BDT adoption following the TOE perspective}

The TOE framework was developed by Tornatzky and Fleischer [12]. They presented a framework determining the factors of IT adoption that can be categorized into three dimensions, namely, technology, organization, and environment. The theory also explains that there are specific factors that influence the adoption of technological innovation in an organization. The technological dimension describes both internal and external technologies that the organization can use [13]. This dimension focuses on how the specific of the innovation being studied can influence its adoption decision [14]. The factors in this dimension are often related to the characteristics of innovation in the Diffusion of Innovations theory (DOI), which are relative advantage, compatibility, complexity, trialability, and observability.

The organizational dimension represents the intra-organizational environment and the organization's resources that allocate the adoption of innovations. Organizational dimension comprises several features of an organization such as the number of employees, IT expertise, top management support and leaders' attitude, hierarchical structure, and slack resources [13]. The environmental dimension represents the external or inter-organizational environment in which the organization operates. The literature often defines this dimension in terms of external pressures (e.g., competitive pressure), external support (e.g., government support) and the regulatory environment [15].

Many empirical studies have confirmed the applications of TOE framework in the prediction of adopting technologies such as CRM [14], e-SCM [16], IoT [17], cloud computing [18] or business analytics [19]. In the specific case of BDT, TOE has been accepted to be a useful perspective to understand its diffusion process. For example, Nguyen and Petersen studied in Norway [13] and Agrawal studied in two big emerging economies of Asia-China and India [20]. Their conceptual models are also grounded on the TOE framework. The results of these studies showed that the relative advantage, complexity, compatibility and security in technology plays a significant role while top management support, IT expertise, and organizational size in organizational dimensions were the significant drivers for BDT adoption. Additionally, external pressures (competitive pressure and trading partner pressure) and support (government support and regulatory support) within the environmental dimension were confirmed as significant antecedents prior to BDT adoption. However, the study results of each country may be applicable only to that country. Therefore, this research focuses on studying factors affecting the decision to adopt BDT and to obtain a model for technology adoption in Thailand.

\subsection{Research model and hypotheses}

This study aims to provide a research model by using the theoretical background of the TOE framework based on a literature review. In technological dimension, DOI theory is applied. Attributes of DOI such as relative advantage, compatibility, and complexity are used as antecedent factors. Moreover, to cover security aspects, security factor is added into consideration. In organizational dimension, perspective of top managers (top management support) and the capability perspective of an organization (IT expertise) are applied. In environment dimension, perspective of external pressure (competitive pressure and trading partner pressure) is applied. The research model is shown in Figure 1.

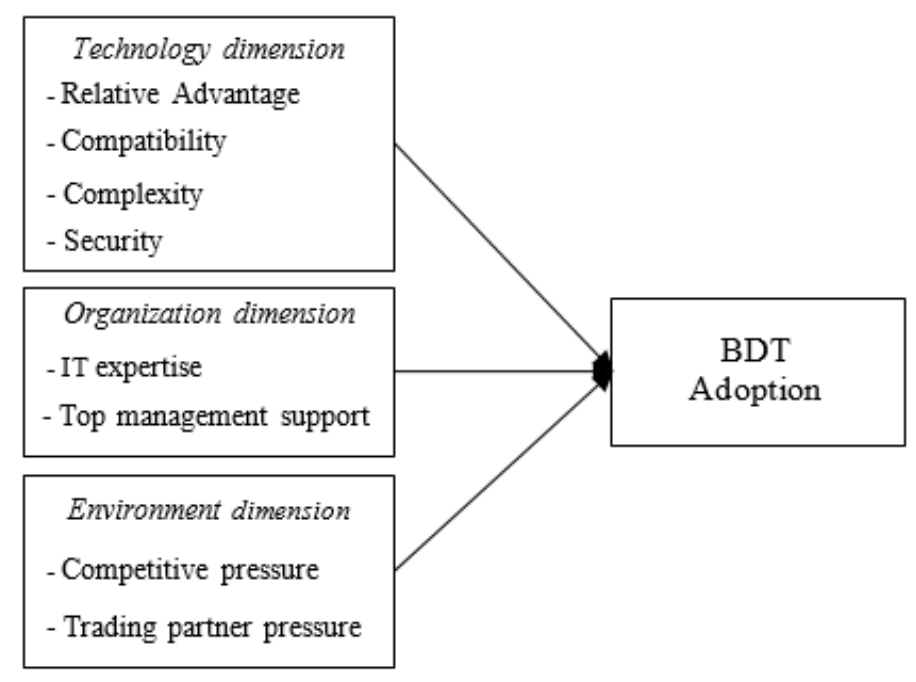

Figure 1. Research model 


\subsubsection{Relative advantage (RA)}

"Relative advantage is the degree to which an innovation is perceived to be better than the idea it supersedes" [21]. Relative advantage has been widely studied and found to be a factor that influences the prediction of innovation adoption and diffusion. For example, Lin [16] investigated the determinants of electronic supply chain management system (e-SCM) adoption in large Taiwanese firms and found that relative advantage positively affected firm decisions to adopt e-SCM.

In the BDT context, relative advantage refers to the degree to which BDT is perceived as providing greater organizational benefit in comparison with traditional databases or data warehouses. Based on the advantage of the technology, BDT can help companies in several aspects such as a large volume data collection, high velocity of data streaming and flexibility in the usage of a variety of data processing including unstructured as well as semi-structured data. BDT can improve efficiency and reduce costs when integrated with other backend systems. Therefore, the first hypothesis is proposed.

H1: Relative advantage has a positive effect on adoption decision of big data technology

\subsubsection{Compatibility (CP)}

"Compatibility is the degree to which an innovation is perceived as consistent with the existing values, past experiences, and needs of potential adopters" [21]. From the above definition, compatibility can be considered in two dimensions. The first dimension is normative or cognitive compatibility such as what adopters feel or think about innovation. The other dimension is compatibility with operational or practical aspects such as compatibility with what the adopters do [13]. This study emphasizes on the latter aspect.

The more users feel compatible with a new technology, the higher possibility users adopt it and facilitate to replace existing technology. Implementing BDT combined with existing process innovations could often lead to better results. At the same time, resisting change can be a key issue in implementing BDT. However, many studies have confirmed that compatibility has a positive effect on the adoption rate. Agrawal [20] investigated the determinants of big data analytics adoption in Asian emerging economies and found that compatibility has a significantly positive effect on organizational decisions to assimilate big data analytics. Thus, according to the literature above, this research proposes the second hypothesis.

H2: Compatibility has a positive effect on adoption decision of big data technology

\subsubsection{Complexity (CPX)}

"Complexity is the degree to which an innovation is perceived as difficult to understand and use". The rate of adoption and complexity of an innovation are negatively related to each other [21]. Researchers have regularly found that complexity is an obstacle to accepting innovation. Complexity was found to have a negative influence on firm decisions to adopt RFID [22]. Wong et al. [23] also found that complexity was negatively related to the decision to adopt blockchain in operations and SCM.

In the context of BDT, complexity is perceived as the difficultly in understanding the ecosystem of the big data solution and integrating BDT with existing information systems and business processes. BDT ecosystem has various layers, the different layers will increase complexity to understand the connections among other software and their functions [1]. BDT should be customized to suit the specific working environment. Moreover, the big data solution requires at least 18-20 days for training, to understand those layers and to comprehend distributed systems in all dimensions. Organizations that perceive the complexity of technology tend to be cautious in adopting technology. Thus, the following hypothesis is expressed.

H3: Complexity has a negative effect on adoption decision of big data technology

\subsubsection{Security (SE)}

"Security is defined as the extent to which a person believes that using a particular application is risk-free [24]. Security is most frequently recognized by the examined adoption in companies [11]. In the context of BDT, new solutions have been developed to ensure more privacy and security. Security features of Hadoop consist of authentication, service level authorization, authentication for web consoles and data confidentiality. Therefore, security is a factor that may be a positive effect on deciding to implement big data in an organization. Thus, the following hypothesis is expressed.

H4: Security has a positive effect on adoption decision of big data technology

\subsubsection{IT expertise (ITX)}

IT expertise is referred to as the knowledge and skill for effectively managing information technology at the organizational level [25]. The literature presents that IT expertise is a major factor in the adoption of new technological innovation in an organization [26]. An organization with existing knowledge of new technological innovations makes adoption effortless. In a big data project, each member of the team must have the expertise and knowledge to work in other sections. Implementing big data requires 
new IT skills such as data analysis, statistics, math, substantive expertise, presentation, and visualization. We can expect that organizations with a higher level of IT expertise are in a better position to adopt BDT. This study, therefore, hypothesizes that:

H5: IT Expertise has a positive effect on adoption decision of big data technology

\subsubsection{Top management support (TMS)}

Top management support plays a key critical factor in technology innovation adoption. Top management support, including the technical and financial resources of an organization, is the degree to which top executive understands the importance and benefits of innovation adoption. Most decisions regularly need support from top management. The study of Oliveira et al. [18] indicated that top management that understands the benefits of cloud computing would readily facilitate the necessary resources and also influenced to implement the change in the organization.

In the context of BDT, the potential advantages of big data to an organization are broad. If top management perceives that the use of BDT is likely to enhance the effectiveness and productivity of an organization's operations, it would influence on the decision to adopt the innovation. In addition, big data involves changes in the whole business processes and top management support is essential to guarantee the allocation of sufficient technical, administrative and financial resources for big data projects [13]. Therefore, this study hypothesizes that:

H6: Top management support has a positive effect on adoption decision of big data technology

\subsubsection{Competitive pressure (CPS)}

Competitive pressure refers to the level of competitive intensity in the industrial environment where the organization operates. Competitive pressure encourages organizations to find competitive advantages by adopting new technologies. These new technologies may lead to an uncertainty in the industrial environment and may increase the competition within the industry. Both cases are believed to increase the demand to adopt and the rate of acceptance of innovation. Previous studies have shown that competitive pressure is an important factor in adopting technology. For instance, the study of Lin and Lin [27] investigated the determinants of e-business diffusion in large Taiwanese firms and found that competitive pressure influenced internal integration and external diffusion of e-business positively. Lin [16] also investigated the determinants of e-SCM adoption in large Taiwanese firms and found that competitive pressure was a key factor of the likelihood of e-SCM adoption.

Recent studies that examined the determinants of organizational adoption of BDT in medium and large companies in Norway also showed that competitive pressure had a positive relationship with the decision to adopt BDT [13]. This suggests that organizations adopt innovation to avoid the risk of competitive pressure. It is therefore hypothesized that organizations tend to adopt BDT when they believe that non-adoption will lead to a competitive disadvantage. Therefore, this study hypothesizes that:

H7: Competitive pressure has a positive effect on adoption decision of big data technology

\subsubsection{Trading partner pressure (TP)}

The pressure imposed by trading partners consists of the potential power of a trading partner to encourage an adoption decision and its strategy to exercise that potential power through recommendations, promises and threats [28]. The recommendation from powerful partners e.g., in adopting a decision in a firm, those who has more power, owns larger portion of the firm's profits or sales, are expected to be more influential than similar recommendations from less powerful partners. In a manufacturing industry in Taiwan, it was found that trading partner pressure was a positive relationship with RFID adoption because many powerful companies or organizations had recently exerted strong pressure on their suppliers to adopt RFID [22].

In the context of BDT, many large purchasers and retailers have come to be aware of the potential benefits of BDT to exploit new opportunities and draw meaningful insights from big data so that partners may be asked to use BDT. Therefore, it is expected that organizations facing pressure from partners will use BDT more than organizations that do not face pressure. Hence, this study hypothesizes that:

H8: Trading partner pressure has a positive effect on adoption decision of big data technology

\section{RESEARCH METHOD}

This study employed quantitative approach based mainly on survey conducting on convenience sampling. The details of methodology, e.g. instruments and data collection method, explained as follows. 


\subsection{Research instrument}

This research uses questionnaire as an instrument. The questionnaire consists of three sections. The first section includes the demographic characteristics, the second section asks about their organizations, and the last part contains the questions for measuring the constructs in the research model. The questionnaire items are extracted from various research studies and modified to suit the BDT context. All constructs are assessed using 7-point Likert-type scales, ranging from 1 for strongly disagree to 7 for strongly agree as anchors for each construct. The reliability of the questionnaire is ensured by a review of the literature and observing composite reliability (CR) values. A pilot study session is conducted to evaluate the reliability of the instrument with 27 samples. The CR of the pilot-test is above 0.7 for all constructs.

\subsection{Data collection method}

The target population in this study were practitioners who were familiar with BDT. Data were collected through online survey from April to June 2019. A total of 331 responses were obtained. Removing missing data resulted in 310 valid cases for analysis (approximately $93.65 \%$ of all received cases). The participant profiles were presented in Table 1.

We obtained a total of 310 respondents from diverse sectors, the highest respondents belong to the government agency $(20.65 \%), 17.42 \%$ belong to technology, and communication and $14.52 \%$ belong to education or research, respectively. Based on the number of employees, $34.52 \%$ of the respondents are from the organizations with more than 2,000 employees, $21.61 \%$ from the organizations having 101 to 500 employees and $13.87 \%$ are from the organizations that have less than or equal to 50 employees.

Table 1. Participants' profile

\begin{tabular}{llll}
\hline & & $\mathrm{N}=310$ & Percentage(\%) \\
\hline Gender & Male & 148 & 47.74 \\
Industry Group & Female & 162 & 52.26 \\
& Agro \& Food Industry & 7 & 2.26 \\
& Consumer Products & 13 & 4.19 \\
& Financial and banking & 43 & 13.87 \\
& Industrials & 8 & 2.58 \\
& Property \& Construction & 7 & 2.26 \\
& Resources & 3 & 0.97 \\
& Services & 23 & 7.42 \\
& Technology and Communication & 54 & 17.42 \\
& Education /Research & 45 & 14.52 \\
& Government agency & 64 & 20.65 \\
State Enterprise Agency & 20 & 6.45 \\
& Other & 23 & 7.42 \\
Number of employees & 43 & 13.87 \\
& 50-100 & 31 & 10.00 \\
& $101-500$ & 67 & 21.61 \\
$501-1,000$ & 39 & 12.58 \\
$1,001-2,000$ & 23 & 7.42 \\
$\leq 2,000$ & 107 & 34.52 \\
\hline
\end{tabular}

\section{RESULTS AND DISCUSSION}

Structural Equation Modeling (SEM) is conducted for evaluating construct validity and testing the hypotheses. We proceed with a two-step procedure. We first examine the measurement model by assessing reliability and validity. We then investigate the strength and the direction of the relationships between the endogenous and exogenous variables of the structure model.

\subsection{The measurement model}

AMOS is used to carry out a confirmation factor analysis (CFA) to evaluate the measurement model. CFA is a confirmation test for the relationship between latent and observed variables. The criteria for the overall model fit testing include the norm chi-square (CMIN/DF), goodness of fit index (GFI), adjusted goodness of fit index (AGFI), the normed fit index (NFI), the comparative fit index (CFI), the Tucker Lewis index (TLI), standardized root mean squared residuals (SRMR), and root mean square error of approximation (RMSEA). The results and recommended values are summarized in Table 2.

Reliability is assessed by using composite reliability (CR). Each construct should be consistent in what it is intended to measure. All constructs have CR above 0.70 (ranging from 0.830 to 0.964 ) and demonstrate internal consistency see in Table 3. Convergent validity indicates the degree to which the items supposed to measure a construct illustrate high correlation with each other. The measuring scale is assessed 
by using two criteria: (1) factor loading of all item should be 0.5 or higher and (2) Average variance extracted (AVE) value of 0.5 or above is recommended for sufficient convergence. Table 4 shows sufficient degrees of convergent validities, as the values of factor loading for all of the items are higher than 0.5 (ranging from 0.689 to 0.974). All AVEs exceed the recommended values of 0.5 (ranging from 0.551 to 0.900). Discriminant validity examines that the items are truly distinct from other constructs. The measuring scale, assessed based on the square root of AVE, is greater than the inter-construct correlations estimates. As indicated in Table 4, the square root of AVE of each construct, shown in diagonal elements, is higher than the inter-construct correlations.

Table 2. Goodness-of-fit indices

\begin{tabular}{lll}
\hline Model fit indices & Results value & Recommend value \\
\hline norm chi-square (CMIN/DF) & 1.651 & CMIN/DF $<3.0$ \\
goodness of fit index (GFI) & 0.895 & $0.90<\mathrm{GFI}$ \\
adjusted goodness of fit index (AGFI) & 0.863 & $0.80<\mathrm{AGFI}$ \\
the normed fit index (NFI) & 0.930 & $0.90<\mathrm{NFI}$ \\
the Tucker Lewis Index (TLI) & 0.964 & $0.90<\mathrm{TLI}$ \\
the comparative fit index (CFI) & 0.971 & $0.90<\mathrm{CFI}$ \\
standardized root mean squared residuals (SRMR) & 0.0392 & SRMR $<0.05$ \\
root mean square error of approximation (RMSEA) & 0.046 & RMSEA $<0.08$ \\
\hline
\end{tabular}

Table 3. Factor loading, reliability, and AVE

\begin{tabular}{|c|c|c|c|c|}
\hline Constructs & Items & Loadings & CR & AVE \\
\hline \multirow[t]{4}{*}{ Relative advantage } & RA1 & 0.836 & 0.830 & 0.551 \\
\hline & RA2 & 0.689 & & \\
\hline & RA3 & 0.723 & & \\
\hline & RA4 & 0.758 & & \\
\hline \multirow[t]{4}{*}{ Compatibility } & CP1 & 0.771 & 0.907 & 0.710 \\
\hline & $\mathrm{CP} 2$ & 0.830 & & \\
\hline & $\mathrm{CP} 3$ & 0.908 & & \\
\hline & $\mathrm{CP} 4$ & 0.855 & & \\
\hline \multirow[t]{3}{*}{ Complexity } & CPX1 & 0.825 & 0.865 & 0.680 \\
\hline & CPX2 & 0.842 & & \\
\hline & CPX3 & 0.807 & & \\
\hline \multirow[t]{3}{*}{ Security } & SE1 & 0.878 & 0.939 & 0.836 \\
\hline & SE2 & 0.938 & & \\
\hline & SE3 & 0.926 & & \\
\hline \multirow[t]{3}{*}{ IT expertise } & ITX1 & 0.861 & 0.900 & 0.750 \\
\hline & ITX2 & 0.901 & & \\
\hline & ITX3 & 0.835 & & \\
\hline \multirow[t]{3}{*}{ Top management support } & TMS1 & 0.839 & 0.872 & 0.696 \\
\hline & TMS2 & 0.940 & & \\
\hline & TMS3 & 0.708 & & \\
\hline \multirow[t]{2}{*}{ Competitive pressure } & CPS2 & 0.808 & 0.832 & 0.713 \\
\hline & CPS3 & 0.879 & & \\
\hline \multirow[t]{3}{*}{ Trading partner pressure } & TP1 & 0.846 & 0.933 & 0.822 \\
\hline & TP2 & 0.970 & & \\
\hline & TP3 & 0.900 & & \\
\hline \multirow[t]{3}{*}{ Behavioral intention } & BI1 & 0.922 & 0.964 & 0.900 \\
\hline & $\mathrm{BI} 2$ & 0.974 & & \\
\hline & $\mathrm{BI} 3$ & 0.950 & & \\
\hline
\end{tabular}

Table 4. Descriptive statistics and correlation

\begin{tabular}{|c|c|c|c|c|c|c|c|c|c|c|c|}
\hline & Mean & S.D. & RA & $\mathrm{CP}$ & CPX & SE & ITX & TMS & CPS & $\mathrm{TP}$ & BI \\
\hline CPX & 3.942 & 1.348 & -0.389 & -0.240 & 0.825 & & & & & & \\
\hline ITX & 4.999 & 1.330 & 0.664 & 0.270 & -0.274 & 0.118 & 0.866 & & & & \\
\hline TMS & 5.614 & 1.356 & 0.737 & 0.459 & -0.192 & 0.126 & 0.603 & 0.834 & & & \\
\hline CPS & 5.623 & 1.084 & 0.412 & 0.626 & -0.158 & 0.203 & 0.228 & 0.339 & 0.844 & & \\
\hline
\end{tabular}

Note :The square root of AVE is shown on the diagonal. 


\subsection{Structure model for hypotheses testing}

The results, shown in Figure 2, indicate that five exogenous variables, that is, relative advantage, security, top management support, competitive pressure, and trading partner pressure are significant supported. Moreover, square multiple correlations, or $\mathrm{R}^{2}$ indicates that value of 0.52 . Thus, the study suggested that exogenous variables in this study can explain the adoption decision at $52 \%$.

The results are summarized in Table 5. Within the technological dimension, we found that relative advantage has a positive relationship with adoption $(\mathrm{p}<0.05)$. Thus, H1 is supported. Security has a negative relationship with adoption ( $\mathrm{p}<0.05$ ) but is in the wrong direction. Thus, H4 is not supported. The path from compatibility and complexity have an insignificant path to adoption. Thus, H2 and H3 are not supported. Within the organizational dimension, IT expertise has an insignificant path to adoption. Thus, H5 is not supported. Top management support has a strong positive relationship with adoption ( $<<0.001)$. Thus, H6 is supported. Within the environmental dimension, competition pressure has a strongly positive relationship with adoption $(\mathrm{p}<0.001)$. Thus, $\mathrm{H} 7$ is supported. We also found that trading partner pressure has a positive relationship with adoption ( $\mathrm{p}<0.05)$. Thus, $\mathrm{H} 8$ is supported.

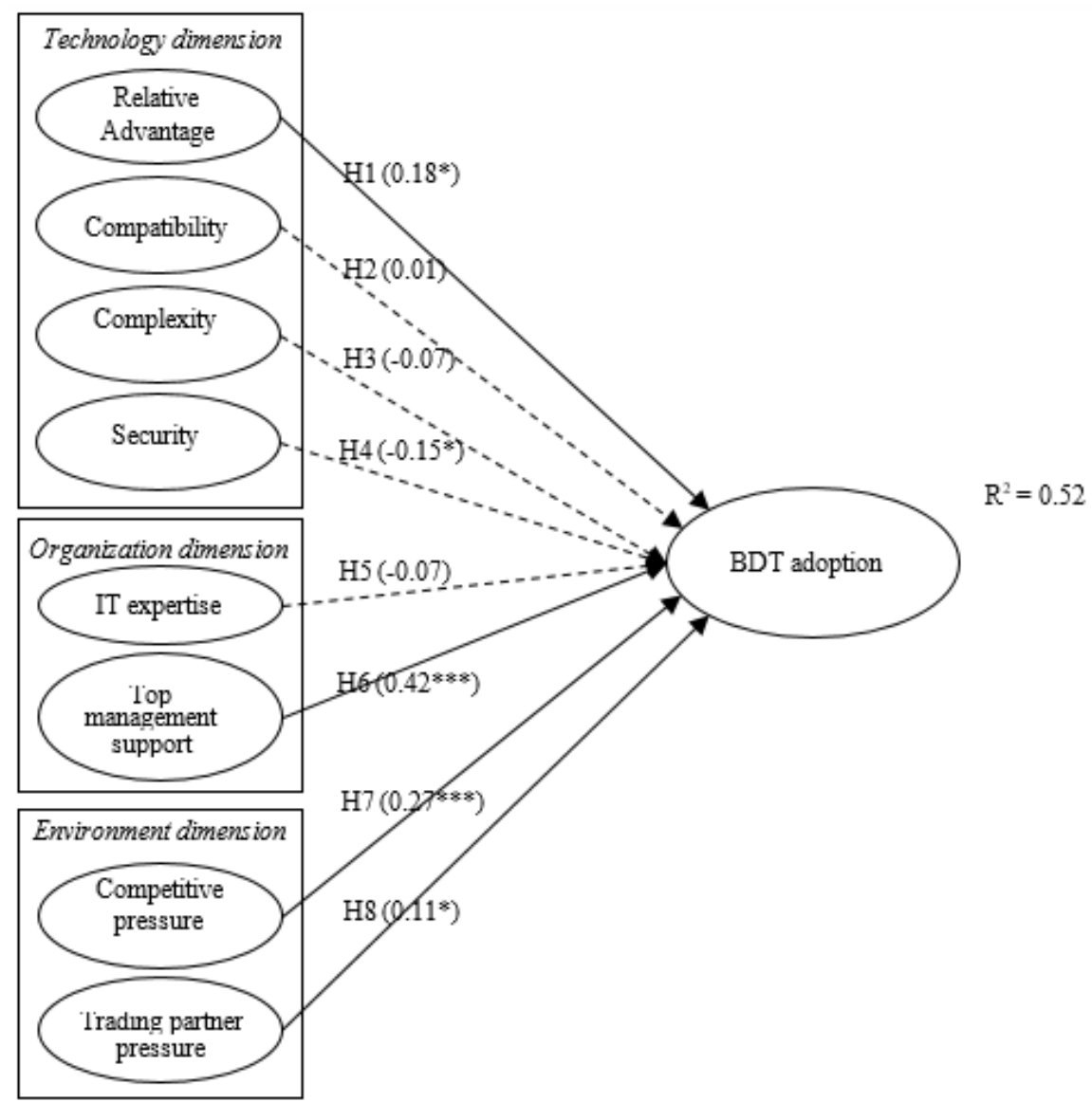

Note: ${ }^{8} p<0.05,{ }^{888} p<0.001$

Figure 2. Research model results

Table 5. Hypothesis testing results

\begin{tabular}{cclrcc}
\hline Dimension & Hypothesis & Parameter & \multicolumn{1}{c}{$\beta$} & $\mathrm{p}$ & Result \\
\hline Technology & H1 & RA -> BI & 0.185 & 0.015 & Supported \\
& H2 & CP -> BI & 0.015 & 0.871 & Not Supported \\
& H3 & CPX -> BI & -0.069 & 0.241 & Not Supported \\
& H4 & SE -> BI & -0.139 & 0.010 & Not Supported \\
Organization & H5 & ITX -> BI & -0.065 & 0.416 & Not Supported \\
& H6 & TMS -> BI & 0.419 & $* * *$ & Supported \\
Environment & H7 & CPS -> BI & 0.272 & $* * *$ & Supported \\
& H8 & TP -> BI & 0.111 & 0.026 & Supported \\
\hline
\end{tabular}




\subsection{Discussion}

Many interesting discoveries arise from the analyses of data. These findings will be discussed based on TOE dimension as follows. In the technology dimension, H1 is supported and is related to relative advantage. This observation is consistent with the findings in [4]. The possible explanation for this finding is that the features of BDT are different from other information systems such as RDBMS and data warehouse. Therefore, the more relative advantage of the new technology offers, the higher the level of adoption. Compatibility is not a significant effect on the adoption, which answers the second hypothesis (H2). These findings suggest that the changes introduced by BDT do not affect decision making stage. $\mathrm{H} 3$ also contradicts our predictions regarding the effects of complexity on decision adoption. A possible explanation for this finding is that it may require the employment of a consultant or an outsourced team to avoid learning and installation difficulties. This finding confirmed previous study [29], which finds that complexity is not significant to adopt the Internet and e-business technologies. Security (H4) has a significant negative effect on the decision to adopt BDT, which is consistent with the previous research [13]. Possible explanations for this could be that BDT is different from the traditional data environment, including tools and methods for protecting data that may cause new forms of security threats. Therefore, security is a factor that inhibits the decision to adopt BDT in the organization.

Within the dimension of the organization, we found that IT expertise had no significant effect on behavioral intention to adopt BDT (H5). This suggests that IT expertise does not play a role in the decision stage in the context of BDT. This finding confirmed the work of Nguyen and Petersen [13], which shows that organizations not only in the initiation stage but also the adoption-decision stage are less aware of the importance of their IT expertise than the companies in the implementation stage. Top management support influences the behavioral intention to adopt BDT and the results have confirmed this relationship (H6). A possible explanation for this finding is that the adoption of BDT could lead to changes in business procedures, and organizational structures [4]. Top management support is a good sign of creating a positive attitude towards innovation and create an enabling environment for acceptance of innovation. Moreover, gaining support from top management ensures that the project has enough resources for the successful adoption of innovation technology. This finding is in line with previous studies [13].

As for the environmental dimension, competitive pressure has influenced the decision to adopt BDT (H7). Today's businesses are driven based on data. If an organization does not adopt BDT, it would be an advantage to competitors. Therefore, when organizations are faced with intense competitive pressure, they are more open to the adoption of BDT. This finding is consistent with those from other studies [13,20]. Trading partner pressure was found to be a significant facilitator of BDT adoption. This is due to the fact that trading partners have an influence in the operation of the business. Their recommendations or promises can influence the decision to adopt BDT. However, this finding is inconsistent with [22].

\section{CONCLUSION}

This study aims to examine the adoption decision of BDT in organizations in Thailand from a technology-organization-environment (TOE) framework perspective. These findings support the suitability of using TOE to understand the determinants that influence the use of BDT in Thai organizations. The measure of the variance of the dependent variable that explained by the independent variables resulted in an $\mathrm{R}^{2}$ value of 0.52 . Relative advantage, top management support, competitive pressure, and trading partner pressure show significant positive relation to BDT adoption. Security negatively influences BDT adoption. The top management support is the major determinant followed by competitive pressure.

\section{IMPLICATIONS}

\subsection{Implications for research}

This study presents a model for studying the decision to adopt BDT in organizations in Thailand. The results of this study have the following implication. Firstly, the contribution of this study is an empirically test of the existing information systems theory in a new context, which is the study on the adoption of BDT in organizations in Thailand. The status of Thailand is different from those of other countries because big data technologies have recently entered the trend in Thailand. Therefore, this study helps to confirm the existing information system theory in a new context. As a result, the proposed model is able to explain 52\% of the technology acceptance of BDT and can thus be applied to other domains.

Secondly, the study presents a model built on the TOE framework. This study combines various perspectives into the proposed model. In terms of technology, research integrates the perceptions of attributes of innovation, including relative advantage, compatibility, and complexity that may affect BDT adoption. In addition, the security determinant is extended for predicting BDT adoption. Organizational factors are 
created from the perspective of top managers and the capability perspective of the corresponding organization. This study proposes that top management support and IT expertise may influence an organization's adoption of BDT. Lastly, competitive pressure and trade partner pressure under the perspective of external pressure serve as the environmental features that may influence the adoption of BDT. This type of TOE model is novel, as it is based on integrating various combinations of theoretically grounded variables.

\subsection{Implications for practice}

The findings of this study provide important practical implications for organizations' decision to adopt BDT. Firstly, both relative advantages and security in the technological dimension have a significant effect on the adoption of BDT. In order to facilitate organizational adoption, those responsible for implementing BDT in an organization need to be fully aware of these factors that are important during the decision-making stage. Security has a negative impact so managers should encourage operators to strictly comply with BDT regulations with the improvements in IT infrastructure. In addition, the training and recruitment of IT employees with security expertise is very important.

Secondly, top management support in the organizational dimension has a significant effect on the adoption of BDT. Thus, it is recommendable to engage top management support at the beginning. Top management should specify BDT in their business strategies and collaborate with specialists for obvious definition of big data and its advantages as well as providing the resources needed for the project.

Lastly, in the environment dimension both competitive pressure and trading partner pressure have a significant positive effect on the adoption of BDT. Managers should be aware that higher external pressure encourages the BDT decision process. Hence, managers should be concerned about the industrial environment and the potential power of the partner when deciding to adopt BDT.

\section{ACKNOWLEDGEMENTS} of Thailand.

This research is supported by Graduate Development Scholarship 2020, National Research Council

\section{REFERENCES}

[1] A. Oussous, F.-Z. Benjelloun, A. Ait Lahcen, and S. Belfkih, "Big Data technologies: A survey," Journal of King Saud University - Computer and Information Sciences, vol. 30, no. 4, pp. 431-448, 2018.

[2] H. G. Sanjay Ghemawat, and Shun-Tak Leung, "The Google File System," Proceedings of the nineteenth ACM symposium on Operating systems principles, pp. 29-43, 2003.

[3] K. Shvachko, H. Kuang, S. Radia, and R. Chansler, "The Hadoop Distributed File System," IEEE 26th symposium on mass storage systems and technologies (MSST), pp. 1-10, 2010.

[4] S. Verma, S. S. Bhattacharyya, and S. Kumar, "An extension of the technology acceptance model in the big data analytics system implementation environment," Information Processing \& Management, vol. 54, no. 5, pp. 791-806, 2018.

[5] T. Oliveira, and M. R. Martins, "Literature Review of Information Technology Adoption Models at Firm Level," vol. 14, no. 1, 2011.

[6] Brandbuffet, "Penetrate the Big Data situation in Thailand, "treasure" giant of the business world," 2018. [Online]. Available: https://www.brandbuffet.in.th.

[7] I. Gartner, "Gartner Glossary," 2019. [Online]. Available: https://www.gartner.com/en/informationtechnology/glossary/big-data

[8] A. Gandomi, and M. Haider, "Beyond the hype: Big data concepts, methods, and analytics," International Journal of Information Management, vol. 35, no. 2, pp. 137-144, 2015.

[9] B. Furht, and F. Villanustre, "Introduction to Big Data," Big Data Technologies and Applications Cham: Springer International Publishing, pp. 3-11, 2016.

[10] T. Erl, W. Khattak, and P. Buhler, "Big Data Fundamentals Concepts, Drivers \& Techniques," 1st ed., United States: Prentice Hall, 2015.

[11] E. Raguseo, "Big data technologies: An empirical investigation on their adoption, benefits and risks for companies," International Journal of Information Management, vol. 38, no. 1, pp. 187-195, 2018.

[12] L. G. Tornatzky, and M. Fleischer, "Processes of Technological Innovation," Lexington, MA: Lexington Books, 1990.

[13] T. Nguyen, and T. E. Petersen, "Technology Adoption in Norway: Organizational Assimilation of Big Data," Master Thesis, Economics and Business Administration, Norwegian School of Economics, 2017.

[14] F. Cruz-Jesus, A. Pinheiro, and T. Oliveira, "Understanding CRM adoption stages: empirical analysis building on the TOE framework," Computers in Industry, vol. 109, pp. 1-13, 2019.

[15] Q. Jia, Y. Guo, and S. J. Barnes, "Enterprise 2.0 post-adoption: Extending the information system continuance model based on the technology-Organization-environment framework," Computers in Human Behavior, vol. 67, pp. 95-105, 2017. 
[16] H.-F. Lin, "Understanding the determinants of electronic supply chain management system adoption: Using the technology-organization-environment framework," Technological Forecasting and Social Change, vol. 86, pp. 80-92, 2014.

[17] D. Lin, C. K. M. Lee, and K. Lin, "Research on effect factors evaluation of internet of things (IOT) adoption in Chinese agricultural supply chain," International Conference on Industrial Engineering and Engineering Management (IEEM), pp. 612-615, 2016.

[18] T. Oliveira, M. Thomas, and M. Espadanal, "Assessing the determinants of cloud computing adoption: An analysis of the manufacturing and services sectors," Information \& Management, vol. 51, no. 5, pp. 497-510, 2014.

[19] D. Nam, J. Lee, and H. Lee, "Business analytics adoption process: An innovation diffusion perspective," International Journal of Information Management, vol. 49, pp. 411-423, 2019.

[20] K. P. Agrawal, "Investigating the Determinants of Big Data Analytics (BDA) Adoption in Asian Emerging Economies," In Academy of Management Annual Meeting Proceedings, vol. 2015, no. 1, pp. 11290-11290, 2015.

[21] E. M. Rogers, "Diffusion of innovations: A Division of Macmillan Publishing Co.," Inc. Third Edition, The Free Pres, New York., 1983.

[22] Y.-M. Wang, Y.-S. Wang, and Y.-F. Yang, "Understanding the determinants of RFID adoption in the manufacturing industry," Technological Forecasting and Social Change, vol. 77, no. 5, pp. 803-815, 2010.

[23] L.-W. Wong, L.-Y. Leong, J.-J. Hew, G. W.-H. Tan, and K.-B. Ooi, "Time to seize the digital evolution: Adoption of blockchain in operations and supply chain management among Malaysian SMEs," International Journal of Information Management, 2019.

[24] D.-H. Shin, "User centric cloud service model in public sectors: Policy implications of cloud services," Government Information Quarterly, vol. 30, no. 2, pp. 194-203, 2013.

[25] M. I. Baig, L. Shuib, and E. Yadegaridehkordi, "Big data adoption: State of the art and research challenges," Information Processing \& Management, vol. 56, no. 6, 2019.

[26] M. A. Hameed, S. Counsell, and S. Swift, "A meta-analysis of relationships between organizational characteristics and IT innovation adoption in organizations," Information \& Management, vol. 49, no. 5, pp. 218-232, 2012.

[27] H.-F. Lin, and S.-M. Lin, "Determinants of e-business diffusion: A test of the technology diffusion perspective," Technovation, vol. 28, no. 3, pp. 135-145, 2008.

[28] C. L. Iacovou, I. Benbasat, and A. S. Dexter, "Electronic data interchange and small organizations: adoption and impact of technology," MIS quarterly, vol. 19, no. 4, pp. 465-485, 1995.

[29] P. Ifinedo, "An Empirical Analysis of Factors Influencing Internet/E-Business Technologies Adoption by SMEs in Canada," International Journal of Information Technology and Decision Making, vol. 10, pp. 731-766, 2011.

\section{BIOGRAPHIES OF AUTHORS}

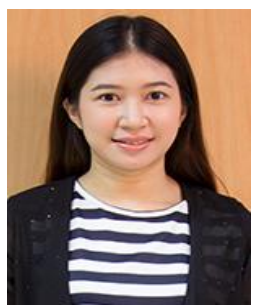

Wanida Saetang is currently a Ph.D. student in the Department of Information Technology at King Mongkut's University of Technology North Bangkok. She was graduated with Bachelor of Computer Science from Srinakharinwirot University where she worked on projects like image retrieval. She pursued her Master of Information Technology Management from King Mongkut's University of Technology North Bangkok where she researched about data mining. Her current research interests are Information Management, Information Theory, Innovations Diffusion, Data Mining and Data Science.

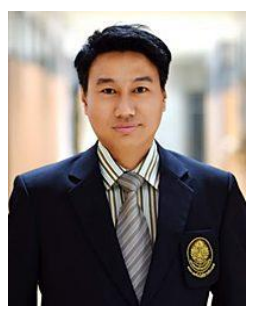

Sakchai Tangwannawit received the professional education with B.S. (Computer Education), M.S.(Information Technology), and Ph.D. (Computer Education) from King Mongkut's University of Technology North Bangkok (KMUTNB), Bangkok, Thailand. He has been working as a lecturer for more than 10 years in the field of Information Technology in the Faculty of Information Technology, KMUTNB.

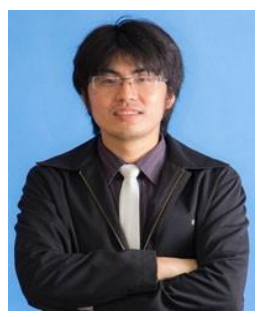

Tanapon Jensuttiwetchakul is currently a lecture at faculty of Information Technology, King Mongkut's University of Technology North Bangkok, Thailand. He Obtained his Ph.D. degree in Information Technology in Business at Faculty of Commerce and Accountancy, Chulalongkorn University. He received his Bachelor and master's degree in electrical engineering from Chulalongkorn University in 2006 and 2008, respectively. 